\title{
Configurações do processo orçamentário: análise de empresas que atuam no Brasil
}

\author{
Daniel Magalhães Mucci \\ https://orcid.org/0000-0002-0658-1470 ｜ E-mail: danielmmucci@usp.br \\ Franciele Beck \\ https://orcid.org/0000-0001-7390-5933 | E-mail: fbeck@furb.br \\ Fabio Frezatti \\ https://orcid.org/0000-0002-5927-022X | E-mail: frezatti@usp.br
}

\section{Resumo}

Objetivo: O presente estudo visa investigar as diferentes configurações do processo orçamentário utilizado por empresas de médio e grande porte que atuam no Brasil, considerando os estágios de planejamento, de execução, de avaliação e características transversais. Este estudo se justifica ao tratar o processo orçamentário de forma holística, levando-se em consideração os perfis de orçamento praticados pelas empresas.

Método: Foi desenvolvido um levantamento abrangendo uma amostra final de 109 empresas de médio e grande porte. Como métodos de análise foram empregados: análise fatorial confirmatória e análise de cluster. Resultados: Ao combinar as dimensões de planejamento, execução, avaliação e aspectos transversais, a análise de clusters sugere diferentes configurações que denotam níveis de maturidade do processo orçamentário, sendo: Orçamento só como discurso, Quase Planejamento, Orçamento Embrionário, Orçamento com estrutura de planejamento estático e Orçamento com estrutura flexível.

Contribuições: $\mathrm{O}$ estudo propõe insights sobre o nível de maturidade do orçamento utilizado por empresas de médio e grande porte, suscitando reflexões a respeito da melhoria do processo orçamentário (dimensões) e ampliação ou delimitação dos papéis que o orçamento desempenha nas empresas.

Palavras-chave: Orçamento; Configurações do Orçamento; Funções do Orçamento; Abordagem Configuracional. 


\section{Introdução}

Nas últimas décadas, uma extensa literatura na área de contabilidade gerencial tem investigado diferentes ângulos do processo orçamentário, sejam as dimensões do mecanismo, sejam seus antecedentes e seus consequentes nas empresas(Covaleski, Evans, Luft, \& Shields, 2003; Shields, 2015; Silva \& Lavarda, 2014; Frezatti, Aguiar, Guerreiro, \& Gouvea, 2011). Podem ser identificados estudos que discutiram oefeito de fatores contingenciais como porte, estratégia, ciclo de vida e incerteza sobre o orçamento (Hansen \& Van der Stede, 2004; Frezatti, Relvas, Nascimento, Junqueira, \& Bido, 2010a) e o impacto do desenho e uso sobre asatitudes, comportamentos e desempenho (Chapman \& Kihn, 2009; Merchant, 1981).

Os estudos anteriores investigaram algumas das características do processo orçamentário, como o nível de participação dos gestores na elaboração do plano (Shields \& Shields, 1998; Brownell \& Dunk, 1991), a dificuldade das metas orçamentárias (Merchant \& Manzoni, 1989), a quantidade de revisões (Merchant, 1981; Van der Stede, 2001) e o uso do orçamento para avaliação de desempenho (Arnold \& Artz, 2019; Hartmann, 2000) e incentivos (Aguiar, Teixeira, Nossa, \& Gonzaga, 2012), havendo lacuna de estudos que tratassem a temática de forma holística (Sponem \& Lambert, 2016). Em outras palavras, apesar do desenvolvimento teórico e evidências empíricas, são poucos os estudos que abordam o orçamento considerando suas diversas características simultaneamente(Libby \& Lindsay, 2010; Frezatti, Relvas, Junqueira, Nascimento, \& Oyadomari, 2010b; Dal Magro \& Lavarda, 2015; Sponem \& Lambert, 2016).

A abordagem configuracional é capaz de gerar uma caracterização rica a respeito do campo prático (Meyer, Tsui, \& Hinings, 1993; Doty \& Glick, 1994; Miller, 1996), o que pode gerar evidênciassobre os diferentes perfis do processo orçamentário utilizado pelas empresas. Essa abordagem tem sido utilizada em estudos recentes na área de contabilidade gerencial (Bedford \& Malmi, 2015; Kruis, Speklé, \& Widener, 2016) e em outros campos específicos, como o de empresas familiares (Dekker, Lybaert,Steijvers, Depaire, \& Mercken, 2013).Frezatti, Aguiar, Guerreiro e Gouvea (2011) trouxeram evidências sobre os perfis de empresas brasileiras, considerando a ênfase no planejamento estratégico e a ênfase no orçamento. Mais recentemente, Sponem e Lambert (2016) desenvolveram uma discussão sobre perfis que refletem as múltiplas características do orçamento, tratando do desenho (por exemplo, nível de formalização, detalhe) e do uso (como acompanhamento de variações, base para incentivos) do orçamento nas empresas. Muito embora os estudos acima sejam relevantes à discussão sobre os perfis de orçamento, ainda é escassa e fragmentada e requer mais evidências que representem outros contextos de negócio em que o orçamento é utilizado.

O presente estudo tem como objetivo investigar as diferentes configurações do processo orçamentário utilizado por empresas de médio e grande porte que atuam no Brasil. A pesquisa consiste em um levantamento a partir do qual se observam onze características relacionadas às etapas de planejamento (participação dos gestores, importância dos planos de ação e nível de dificuldade das metas orçamentárias), execução (análise de variações, revisões e reforecasts)e avaliação (avaliação de desempenho e recompensas), assim como as características transversais que tangenciam todo o processo(envolvimento dos gestores seniores, nível de detalhe e nível de formalização do orçamento). Além das características do processo orçamentário, este estudo investiga as funções desempenhadas pelo orçamento e fatores contingenciais (que podem estar relacionados a esse conjunto de características). 
Portanto, apoiado nas características discutidas por Sponem e Lambert (2016), este estudo se justifica no sentido de refletir sobre as características do processo orçamentário no contexto brasileiro, considerando que em diferentes contextos podem emergir diferentes configurações. Há evidências de que os países emergentes são sujeitos a maiores níveis de riscos e incertezas no âmbito econômico e institucional se comparados a países desenvolvidos (Xu \& Meyer, 2013), o que tende a afetar os mecanismos de gestão implementados nas organizações, por exemplo, em ambientes de maior incerteza, as empresas tendem a utilizar com maior frequência práticas de orçamento flexíveis e ter um processo mais participativo. Como contribuições, o estudo se propõe a trazer evidências sobre as configurações de orçamento utilizadas por empresas que atuam no Brasil, promovendo uma visão ampla de uma prática que é complexa e multifacetada (Sponem \& Lambert, 2016; Frezatti et al., 2011; 2010b; Dal Magro \& Lavarda, 2015) e que tem implicações sobre o Sistema de Controle Gerencial (SCG) das organizações (Bedford \& Malmi, 2015; Kruis et al., 2016; Malmi \& Brown, 2008).Além disso, o estudo propõe uma discussão ampla do processo orçamentário, complementando estudos nacionais que discutiram algumas das características de desenho do orçamento e suas consequências gerenciais(Dani, Zonatto, \& Diehl, 2017; Zonatto, Nascimento, Lunardi, \& Degenhart, 2020), bem como os que estudaram a prática orçamentária no contexto de uma organização (Junqueira, Caliman, Frezatti, \& Gonzaga, 2018; Mucci, Frezatti, \& Dieng, 2016; Hillen \& Lavarda, 2020). O presente artigo também agrega aos achados de estudos sobre orçamento empresarial em segmentos específicos (por exemplo, Codesso \& Lunkes, 2016), ao trazer evidências sobre empresas que atuam em diversos setores.

Este artigo propõe cinco clusters que representam diferentes configurações, as quais denotam as características do processo orçamentárioem empresas que atuam no Brasil sendo:Orçamento só como discurso, Quase Planejamento, Orçamento Embrionário, Orçamento com estrutura de planejamento estática e Orçamento com estrutura flexível. Cabe destacar que por emergir do campo, apesar de os construtos utilizados serem baseados em Sponem e Lambert (2016), outros perfis de orçamento puderam ser identificados e discutidosneste estudo. Além das dimensões do desenho e uso do orçamento, o estudo exploratambém as funções que o orçamento desempenha, bem como as características organizacionais e ambientais das empresas classificadas em cada um dos grupos. Por fim, além da perspectiva quantitativa explorada por meio dos clusters, o estudo incorpora também as percepções de executivos respondentes do surveysobre o processo orçamentário, as quais são discutidas em cada um dos cinco perfis de orçamento que emergiram do campo prático.

\section{Revisão de Literatura}

\subsection{Abordagem Configuracional}

A abordagem configuracional tem contribuído para o avanço de pesquisas no campo gerencial e está presente tanto em estudos seminais (Miles \& Snow, 1978; Mintzberg, 1979) quanto em pesquisas recentes (Kruis et al., 2016; Bedford \& Malmi, 2015; Neubaum, Kammerlander, \& Brigham, 2019). Essa abordagem permite que as organizações e/ou mecanismos sejam investigados como arranjos multidimensionais de múltiplos componentes, mecanismos, atributos ou elementos inter-relacionados (Dess, Newport, \& Rasheed, 1993; Meyer et al., 1993; Bedford \& Malmi, 2015). Nesse sentido, a abordagem configuracional é adotada por estudos a fim de identificar, a partir de um conjunto de atributos organizacionais ou de mecanismos de gestão, diferentes grupos ou perfis que têm características heterogêneas entre si. Em outras palavras, o principal pressuposto da abordagem configuracional é que os componentes, atributos e/ou mecanismos organizacionais se agrupem de maneira sistemática para formar grupos ou arranjos limitados e estáveis no tempo (Bedford \& Malmi, 2015). Na literatura organizacional, diversos termos são usados para configurações como taxonomias, tipologias, arquétipos, formas organizacionais. Cabe destacar que, enquanto as taxonomias são baseadas nas evidências a arranjos percebidos no campo prático, as tipologias e demais terminologias normalmente são atribuídas a partir de teorias, construtos, ou seja, conceitualmente. 
Em particular, o presente estudo pauta-se na discussão e apresentação de uma taxonomia referente às configurações do processo orçamentário em empresas de médio e grande porte que atuam no Brasil, uma vez que parte do campo prático. As taxonomias partem do pressuposto indutivo, ou seja, de que as configurações emergem do campo e nesse sentido são observadas na prática (Meyer et al., 1993). As taxonomias permitem descrições mais completas de como os mecanismos e seus atributos são interrelacionadosna prática revelando alternativas quanto aos arranjos de desenho e uso de mecanismos gerenciais como o orçamento empresarial (Sponem \& Lambert, 2016). Além de propor as taxonomias, a abordagem configuracional preocupa-se em gerar insights que possam subsidiar futuros estudos empíricos com natureza preditiva,apartir da compreensão dessas configurações (Miller, 1996).

Recentemente, pesquisadores de contabilidade gerencial recorreram à abordagem da configuração para discutir fenômenos complexos de controle gerencial como, por exemplo, a estrutura das Alavancas de Controle (Kruis et al., 2016), as configurações organizacionais (Bedford \& Malmi, 2015) e o desenho e uso do orçamento empresarial (Sponem \& Lambert, 2016) com o intuito de identificar perfis de desenho e uso dos mecanismos gerenciais que emergem do campo prático.

\subsection{Configurações do Orçamento}

O processo orçamentário envolve uma combinação de características de desenho e uso (Abernethy \& Brownell, 1999; Libby \& Lindsay, 2010) que cumprem diversas funções nas organizações (Hansen \& Van der Stede, 2004), tendo em vista sua complexidade e inserção dentro do processo de gestão da organização (Frezatti, 2009). Pesquisas anteriores na área de orçamento adotaram a abordagem configuracional para discutir tipologias e taxonomias do processo orçamentário baseadas em características que foram tratadas de forma específica ou holística (Hopwood, 1972; Merchant, 1981; Abernethy \& Brownell, 1999; Van der Stede, 2001; Sponem\& Lambert 2016).

Hopwood (1972) discutiu osestilosde orçamento considerando a característica do uso das informações para avaliação de desempenho dos gestores. Nesse sentido, o autor definiu o estilo de uso restrito (constraint), de lucro consciente do orçamento (profitconscious) e o uso insignificante para a avaliação de desempenho (nonaccounting).

Merchant (1981), por sua vez,propôs que orçamentos em que haja participação forte dos gestores no processo e a existência de sistemas de comunicação formal sofisticados sejam denominados de controle orçamentário administrativo e que os orçamentos com forte participação dos gestoresque, no entanto, possuem uma comunicação mais informal sejam denominados de controle orçamentário interpessoal. Já Van der Stede (2001) debateu os tipos de orçamento considerando as dimensões de alcance das metas orçamentárias, revisões orçamentárias, nível de detalhe do orçamento, tolerância para desvios e intensidade do canal de comunicação do orçamento, a partir das quais emergiram os perfis decontrole orçamentário rígido e o controle orçamentário flexível.

Outras características foram investigadas considerando as lentes teóricas e modelos como o das Alavancas de Controle (Simons, 1995) eo da burocracia (Adler \& Borys, 1996). Abernethy e Brownell (1999), os quais, por exemplo, discutiram os usos diagnóstico e interativo do orçamento, a partir do modelo das Alavancas de Controle propostas por Simons (1995) eChapman e Kihn (2009), aplicaram os conceitos relacionados à capacidade de reparo, à transparência interna, à transparência global e à flexibilidade oriundos da burocracia para investigarem o uso facilitador e coercivo do sistema orçamentário. 
Mais recentemente Sponem e Lambert (2016), a partir de uma abordagem configuracional, discutiram múltiplas dimensões do orçamento as quais foram divididas em: (i) estágio do plano (participação dos gestores, importância dos planos de ação e nível de dificuldade das metas orçamentárias); (ii) estágio da ação (análise de variações orçamentárias, revisões orçamentárias e reforecasts); (iii) estágio de avaliação (avaliação de desempenho e recompensas); e (iv) características transversais (envolvimento dos gestores seniores, nível de detalhe e nível de formalização do orçamento). A partir de análise de clusters com essas dimensões, Sponem e Lambert (2016) propuseram cinco tipos de orçamento:o orçamento padrão caracterizado por forte envolvimento dos gestores, de participação dos gestores na proposição das metas orçamentárias e na análise de variação, por outro lado, baixo nível de revisões e reestimativas; o orçamento coercitivo é qualificado por baixo nível de participação na proposição de metas, na negociação e de revisões, bem comopelouso extenso do orçamento para avaliação de desempenho e para balizar o sistema de recompensas;o orçamento interativo é distinguido por uma forte aderência às principais dimensões expostas (participação e de negociação das metas orçamentárias, acompanhamento, reestimativas, envolvimento, detalhe, formalização), por outro lado, apresentando baixo nível de dificuldade das metas orçamentárias; o orçamento frouxoé pouco utilizado para avaliação de desempenho e recompensas,mas exibe o maior nível de revisões orçamentárias; por fim, $\mathrm{o}$ orçamento indicativo apresenta baixo nível de participação e envolvimento dos gestores, nível de detalhe e formalização, no entanto caracteriza-se por um nível alto de dificuldade das metas orçamentárias.

\subsection{Modelo Teórico da Pesquisa}

De forma geral, os estudos que discutiram as configurações do orçamento apresentamum foco em uma ou algumas das dimensões do artefato, com exceção do estudo de Sponem e Lambert (2016), que consideraram múltiplas características conforme mencionado anteriormente. O presente artigo busca expandir a discussão de perfis de desenho do processo orçamentário para outro contexto econômico, social e cultural, no sentido de agregar para a literatura e para a discussão dos inúmeros tipos de orçamento.

Nesse sentido, a partir da abordagem configuracional, o artigo discuteperfis de orçamentosque emergem da prática em empresas de médio e grande porte que atuam no Brasil, considerando oestágio do plano, o estágio de execução, o estágio de avaliação e as características transversais, abrangendo a análise de onze atributos (Etapa 1) segundo Sponem e Lambert (2016). O estágio do plano reflete a etapa de planejamento orçamentário que, dentro da lógica tradicional, é normalmente conduzido no segundo semestre do ano anterior ao de vigência do orçamento. O planejamento orçamentário envolve a elaboração dos planos operacionais (marketing, produção, suprimentos, gastos de overhead) e o plano financeiro (projeção das demonstrações financeiras) (Frezatti, 2009). Dentre as dimensões capturadas dentro do estágio do plano estão a participação dos gestores na proposição das metas orçamentárias, a definição de planos de ação a serem implementados, bem como, qualitativamente, o nível de dificuldade atribuído às metas definidas no plano orçamentário. O estágio de execução reflete o acompanhamento do orçamento versuso resultado realizado denominado de análises de variações, assim como, em caso de demanda das áreas e dos gestores, a revisão das metas orçamentárias em vistas de mudanças no ambiente da organização, por exemplo. O estágio de avaliação normalmente ocorre durante a implementação do orçamento, mas seguido de rituais formais e/ou informais específicos como a realização de reestimativas, considerando o cenário real e as projeções futuras, o monitoramento e a avaliação das atividades desempenhadas pelos gestores e o cumprimento das metas definidas às respectivas áreas, bem como a vinculação dessas metas ao sistema de recompensas como a participação nos resultados/gainsharing. Além disso, o modelo proposto por Sponem e Lambert (2016) define três características que permeiam as etapas acima mencionadas do processo orçamentário, considerando o envolvimento dos gestores seniores nesse processo, o nível de detalhamento das informações e metas no orçamento, e o nível de formalização do processo orçamentário, em termos de prazos, procedimentos e rituais. De forma geral, esses elementos do processo orçamentário foram discutidos em livros texto e em artigos científicos (e.g., Frezatti, 2009; Libby \& Lindsay, 2010; Dal Magro \& Lavarda, 2015; Sponem \& Lambert, 2016). 
Após a definição dos perfis de orçamento com base nas onze dimensões apresentadas anteriormente, esses perfis serão analisados em relação às funções do processo orçamentário (estratégica, gerencial, administrativa e reporte). As funções do orçamento compreendem, conforme Sponem e Lambert (2016): (i) o papel estratégico (implementação da estratégia, previsão, necessidades financeiras, gerenciamento de riscos e coordenação de atividades de negócios); (ii) o papel gerencial (avaliação, incentivos, compromisso); (iii) o papel administrativo (autorização de gastos e alocação de recursos); e (iv) o papel de reporte às partes interessadas externas. Em específico, busca-se discutir, a partir do desenho da pesquisa, que as características do processo orçamentário das médias e grandes empresas que atuam no Brasil sãonorteadaspelas funções que o orçamento desempenha na organização, bem como pelos fatores contingenciais, como, por exemplo, o porte, setor de atuação da empresa, nível de incerteza a que a empresa está exposta, assimcomo a experiência de atuação em outros países (Etapa 2). Essa análise conjunta permite gerar reflexões a respeito da relação desses fatores com as configurações do processo orçamentário de empresas que atuam no Brasil. Na Figura 1, apresenta-se o desenho do presente estudo.

Etapa 1. Configurações do Processo Orçamentário

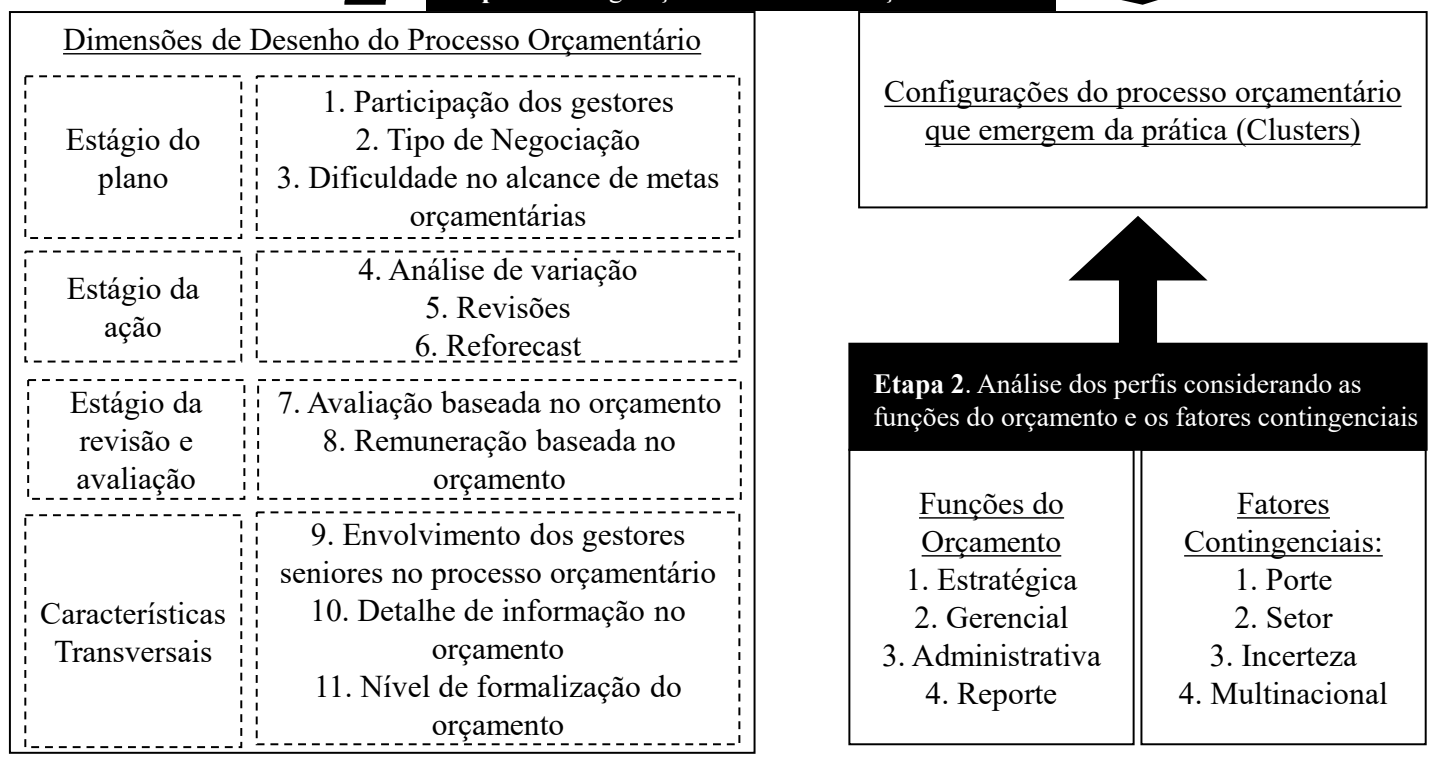

Figura 1. Desenho da pesquisa

Nota. As dimensões de desenho e funções do processo orçamentário estão alinhadas com aquelas discutidas por Sponem e Lambert (2016).

Este artigo alinha-se à literatura que explica que as práticas de gestão podem variar de acordo com variáveis contingenciais (Chenhall, 2003; Otley, 2016). Adicionalmente, ao se considerar as variáveis de incerteza, porte, setor e atuação internacional, o presente estudo busca captar o contexto em que as empresas que atuam no Brasil estão expostas e, por conseguinte, discutir o reflexo deste ambiente em relação às configurações do orçamento nessas empresas.Pelo fato de o Brasil ser um país emergente, as empresas encaram inúmeros desafios (de ordem econômica, política, social) que podem ser captados pelo nível de incerteza a que a empresa está exposta e variar de acordo com o setor ou mesmo porte (Young, Tsai, Wang, Liu,\&Ahlstrom, 2014). 


\section{Metodologia}

\subsection{Coleta de Dados}

O artigo adota a coleta de dados por meio de questionários (survey) com gestores de empresas de médio e grande porte que atuam no Brasil.Destaca-se que esta é uma das principais abordagens metodológicas aplicadas em estudos da área de contabilidade gerencial (Van der Stede, Young, \& Chen, 2005; Speklé \& Widener, 2018). A população de empresas foi definida a partir de duas bases de dados: (i) a publicação Valor 1000 cujas empresas foram contatadas por meio do LinkedIn; e (ii)uma lista profissional privada de 3.200 contatos de e-mail de executivos de finanças. A coleta de dados foi realizada entre maio de 2018 e março de 2019. A partir dessa população, foram recebidos 115 questionários completos, dos quais cinco respostas foram excluídas, visto que não se encaixavam no critério de porte (número de empregados inferior a 50), conforme a definição de pequenas, médias e grandes empresas da União Europeia (European Commission, 2003).

A amostra é composta em sua maioria por empresas de grande porte em termos de funcionários (segundo critérios da União Europeia), já que $86 \%$ das empresas respondentespossuem acima de 250 funcionários. Em relação ao setor, a amostra é predominantemente composta por empresas que atuam no setor de serviços (44\%) e no setor industrial (40\%). Em se tratando da área de atuação, os respondentes são principalmente executivos da área de finanças, gestão e contabilidade (81\%) e que reportam ao conselho de administração (54\%) e à diretoria executiva (37\%). Em outras palavras, os respondentes da pesquisa possuem atuação na área financeira e em cargos de alto nível hierárquico nas organizações, os quais possuem a visão ampla acerca de um mecanismo que tradicionalmente abrange as diversas áreas organizacionais, como é o caso do processo orçamentário.

\subsection{Instrumento de Coleta de Dados}

Os instrumentos da pesquisa foram recentemente validados e utilizados por Sponem e Lambert (2016). Todos os itens são baseados em uma escala Likert de cinco pontos, com exceção do reforecast que possui um item que remete à frequência em que as reestimativas são realizadas na organização. Ao total, foram coletadas respostas em relação a 30 itens.

Como variáveis adicionais para a discussão dos clustersno contexto brasileiro foram utilizadas as seguintes variáveis: as funções do orçamento e as características contingenciais. Utilizou-se o mesmo instrumento aplicado por Sponem e Lambert (2016) para captar as funções do orçamento nas empresas, que compreende: (i) o papel estratégico (implementação da estratégia, previsão, necessidades financeiras, gerenciamento de riscos e coordenação de atividades de negócios); (ii) o papel gerencial(avaliação, incentivos, compromisso); (iii) o papel administrativo (autorização de gastos e alocação de recursos); e (iv) o papel de reporte às partes interessadas externas.

Já em relação às características contingenciais, utilizamos o instrumento adaptado de Kruis et al. (2016), que compreende pressão, imprevisibilidade e incerteza do ambiente e é composto por uma escala de três itens. O setor da empresa foi segregado nas categorias de indústria, comércio e serviço. Em relação ao porte seguiu-se o número de funcionários caracterizando empresas de médio e grande porte (European Commission, 2003). Por fim, analisamos se a empresa tem atuação internacional, nesse sentido se o respondente considera a empresa multinacional.

Cabe destacar que, ao final de cada bloco de questões relacionadas às etapas do processo orçamentário, foram inseridos espaços para comentários espontâneos dos respondentes, os quais nos permitiram aprofundar sobre alguns aspectos qualitativos relacionado sao processo orçamentário da empresa. Nesse sentido, o estudo incorpora esses recortes na análise de cada um dos cinco perfis de orçamento que emergiram do campo prático. 


\subsection{Procedimentos de Análise de Dados}

Os procedimentos de análise de dados utilizados no presente artigo podem ser divididos em algumas etapas, sendo: a Análise Fatorial Confirmatória (AFC), a Análise de agrupamentos (hierárquico e K-médias), bem como a análise descritiva de cada cluster (Hair Jr., Black, Babin, Anderson, \& Tatham, 2009).

Primeiramente, os construtos da pesquisa foram validados por meio da AFC, realizada no software SmartPLS 3.0. Segundo Hair Jr., Hult, Ringle e Sarstedt(2016), a AFC abrange a confiabilidade composta, a validade convergente e a validade discriminante. Na Tabela 1,apresentamos os parâmetros da confiabilidade composta, cujo critério é que seja superior a 0,7 . Em relação à validade convergente e discriminante, utilizou-se a matriz de cargas fatoriais, bem como a matriz de Fornell e Lacker (Tabela 1). A Variância Média Extraída (AVE) deve ser superior a 0,5 indicando validade convergente. Por meioda Matriz de Fornell e Lacker é possível observar validade discriminante nas variáveis do estudo, pois os valores abaixo da diagonal são inferiores àqueles da diagonal (raiz quadrada da AVE), por exemplo, a confiabilidade composta da variável latente participação dos gestores é 0,918 e a AVE é 0,788.

Tabela 1

Análise da Matriz de Fornell e Lacker

\begin{tabular}{|c|c|c|c|c|c|c|c|c|c|c|c|}
\hline & 1 & 2 & 3 & 4 & 5 & 6 & 7 & 8 & 9 & 10 & 11 \\
\hline 1. Participação dos gestores & 0,888 & & & & & & & & & & \\
\hline 2. Tipo de negociação & 0,566 & 0,823 & & & & & & & & & \\
\hline 3.. Dificuldade no alcance de metas & $-0,297$ & $-0,316$ & 0,752 & & & & & & & & \\
\hline 4. Análise de Variação & 0,640 & 0,682 & $-0,270$ & 0,842 & & & & & & & \\
\hline 5. Reforecast & 0,170 & 0,305 & $-0,048$ & 0,360 & 0,789 & & & & & & \\
\hline 6. Revisões & $-0,210$ & $-0,073$ & 0,120 & $-0,149$ & 0,186 & 1,000 & & & & & \\
\hline 7. Avaliação de desempenho & 0,425 & 0,340 & $-0,121$ & 0,533 & 0,143 & $-0,253$ & 0,838 & & & & \\
\hline 8. Recompensas & 0,398 & 0,305 & $-0,123$ & 0,446 & 0,034 & $-0,271$ & 0,653 & 0,942 & & & \\
\hline 9. Envolvimento de executivos & 0,728 & 0,517 & $-0,176$ & 0,712 & 0,193 & $-0,193$ & 0,439 & 0,466 & 0,848 & & \\
\hline 10. Nível de detalhe & 0,598 & 0,431 & $-0,215$ & 0,587 & $-0,011$ & $-0,270$ & 0,388 & 0,384 & 0,726 & 0,903 & \\
\hline 11. Formalização & 0,535 & 0,409 & $-0,316$ & 0,494 & $-0,091$ & $-0,265$ & 0,255 & 0,273 & 0,585 & 0,700 & 0,902 \\
\hline Confiabilidade Composta & 0,918 & 0,722 & 0,893 & 0,878 & 0,762 & 1,000 & 0,940 & 0,876 & 0,885 & 0,898 & 0,897 \\
\hline Variância Média Extraída (AVE) & 0,788 & 0,565 & 0,678 & 0,708 & 0,622 & 1,000 & 0,887 & 0,703 & 0,720 & 0,815 & 0,814 \\
\hline
\end{tabular}

Após a AFC, os escores padronizados das variáveis latentes foram inseridos no software $\mathrm{SPSS}^{\circledast}$ para o desenvolvimento da análise de clusters. Conforme recomendado por Hair Jr. et al (2009), realizou-se o procedimento do cluster hierárquico com o objetivo de estabelecer o número de grupos e identificar possíveisoutliers e, em seguida, o método não hierárquico K-médias. A medida de similaridade escolhida foi a distância quadrática euclidiana e o método de agrupamento que prioriza a menor média das distâncias entre todos os pares (average linkage). A partir da análise do dendograma,identificaram-se umoutlier (o qual foi deletado na amostra) e soluções plausíveis de agrupamentos com quatro ou cinco grupos, considerando-se a linha de corte do dendrograma e a quantidade de empresas por cluster. Definiu-se por apresentar neste artigo a análise de cluster K-médias com cinco grupos, apoiado no artigo de Sponem e Lambert (2016), na quantidade de empresas por grupo e nas diferenças entre os grupos. Ao utilizar cinco grupos é possível identificar diferenças nas médias entre esses grupos a 5\% de nível de significância, a partir do teste ANOVA. 


\section{Análise dos Clusters}

A Tabela 2 apresenta os resultados do cluster K-médias, considerando a solução com cinco grupos. $\mathrm{Na}$ Tabela 2,são indicadas as médias dos escores fatoriais padronizados para cada cluster, bem como o resultado do teste ANOVA, que sugere que existem diferenças estatisticamente significantes entre os clusters. A partir das características de cada cluster, e alinhado com a literatura (Sponem \& Lambert, 2016; Hansen \& Van der Stede, 2004), propõe-se a discussão das seguintes configurações do processo orçamentário: (i) Orçamento só como discurso ( $\mathrm{n}=9$ ); (ii) Quase Planejamento ( $\mathrm{n}=34$ ); (iii) Orçamento Embrionário ( $\mathrm{n}=18$ ); (iv) Orçamento com estrutura de planejamento estático $(n=23)$; e (v) Orçamento com estrutura flexível $(n=25)$. Cabe enfatizar que essas terminologias foram discutidas pelos autores com base nas características do processo orçamentário em cada um dos grupos e da literatura sobre a temática (Hopwood, 1972; Merchant, 1981; Abernethy \& Brownell, 1999; Van der Stede, 2001; Chapman \& Kihn, 2009; Sponem \& Lambert, 2016). A Figura 2 apresenta os escores fatoriais em formato gráfico, permitindo a visualização das características predominantes dentro de cada cluster, bem como as distintivas entre clusters.

Tabela 2

Características do orçamento nos diferentes clusters com base nas onze dimensões

\begin{tabular}{lcccccc}
\hline & $\begin{array}{c}\text { Cluster } \mathbf{1} \\
\mathbf{( n = 9 )}\end{array}$ & $\begin{array}{c}\text { Cluster 2 } \\
\mathbf{( n = 3 4 )}\end{array}$ & $\begin{array}{c}\text { Cluster 3 } \\
(\mathbf{n = 1 8})\end{array}$ & $\begin{array}{c}\text { Cluster 4 } \\
(\mathbf{n = 2 3})\end{array}$ & $\begin{array}{c}\text { Cluster 5 } \\
(\mathbf{n = 2 5})\end{array}$ & $\begin{array}{c}\text { ANOVA } \\
\text { (Sig.) }\end{array}$ \\
\hline Participação dos gestores & $-1,52$ & $-0,71$ & 0,39 & 0,58 & 0,70 & 0,00 \\
\hline Tipo de negociação & $-1,86$ & $-0,34$ & 0,36 & 0,27 & 0,62 & 0,00 \\
\hline Dificuldade no alcance de metas & 0,48 & 0,39 & 0,03 & 0,11 & $-0,83$ & 0,00 \\
\hline Análise de Variação & $-2,46$ & $-0,38$ & 0,40 & 0,51 & 0,64 & 0,00 \\
\hline Reforecast & $-1,22$ & 0,25 & 0,31 & $-0,97$ & 0,77 & 0,00 \\
\hline Revisões & 0,55 & 0,27 & $-0,06$ & $-0,68$ & 0,10 & 0,00 \\
\hline Avaliação de desempenho & $-1,74$ & $-0,02$ & $-0,55$ & 0,66 & 0,43 & 0,00 \\
\hline Recompensas & $-1,20$ & $-0,25$ & $-1,06$ & 0,88 & 0,73 & 0,00 \\
\hline Envolvimento de executivos & $-1,66$ & $-0,75$ & 0,43 & 0,67 & 0,69 & 0,00 \\
\hline Nível de detalhe & $-1,46$ & $-0,69$ & 0,40 & 0,77 & 0,47 & 0,00 \\
\hline Formalização & $-1,43$ & $-0,62$ & 0,48 & 0,67 & 0,40 & 0,00 \\
\hline
\end{tabular}

Nota 1. Os valores apresentados na tabela consistem na média dos valores dos escores fatoriais padronizados para cada cluster. Nota 2. As cores diferenciam as etapas de planejamento (verde), execução (amarelo) e avaliação (vermelho), assim como as características transversais (cinza). As cores mais fortes (para cada linha) sinalizam uma maior aderência da dimensão ao cluster, enquanto as cores mais fracas (para cada linha) refletem a ausência da dimensão no respectivo cluster.

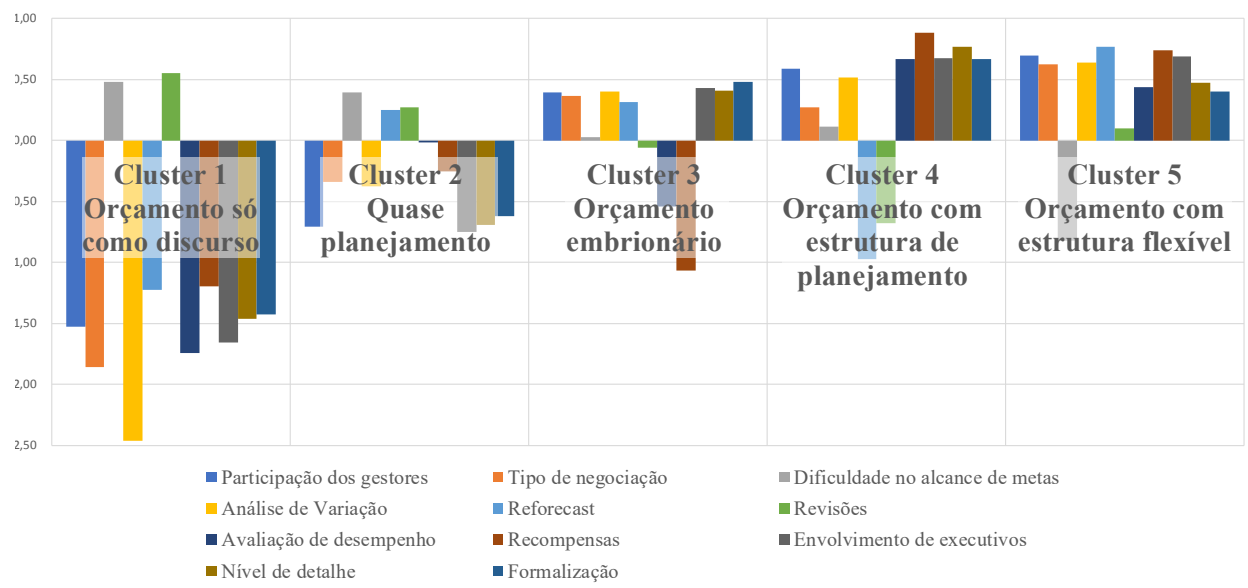

Figura 2. Características do orçamento nos diferentes clusters

Nota 1.0 eixo vertical consiste na média dos valores dos escores fatoriais padronizados para cada Cluster. Essas médias são apresentadas na Tabela 2. 
Além das dimensões utilizadas para o desenvolvimento das configurações do processo orçamentário (vide Tabela 2), também foram utilizadas variáveis para discutir as características de cada grupo, considerando as funções do orçamento (papel estratégico, gerencial, administrativo e de reporte), bem como o contexto organizacional em termos da incerteza ambiental, do porte e setor da organização e se a empresa é multinacional. Essas características complementam a análise de clusters e são apresentadas na Tabela 3 e na Figura 3. Percebe-se que há diferenças significativas entre as médias das funções do orçamento e da incerteza em relação aos clusters (conforme teste ANOVA).No entanto, não é possível realizar associações entre as variáveis porte, setor estatus multinacional com os grupos identificados (vide teste qui-quadrado). Portanto, a análise se concentrou nos atributos que apresentaram distinção entre os clusters, a partir dos testes ANOVA e Qui-quadrado.

Tabela 3

Características das empresas nos diferentes clusters considerando as funções do orçamento e fatores contingenciais

\begin{tabular}{ccccccc}
$\begin{array}{c}\text { Cluster } \\
\mathbf{1}\end{array}$ & $\begin{array}{c}\text { Cluster } \\
\mathbf{2}\end{array}$ & $\begin{array}{c}\text { Cluster } \\
\mathbf{3}\end{array}$ & $\begin{array}{c}\text { Cluster } \\
\mathbf{4}\end{array}$ & $\begin{array}{c}\text { Cluster } \\
\mathbf{5}\end{array}$ & $\begin{array}{c}\text { Total } \\
\text { Geral }\end{array}$ & $\begin{array}{c}\text { Teste ANOVA }^{1} \\
\text { Teste Qui-quadrado }^{2}\end{array}$ \\
\hline
\end{tabular}

\begin{tabular}{lcccccc}
\hline Funções do orçamento $^{1}$ & & & & \\
\hline Papel Estratégico & $-2,211$ & $-0,217$ & 0,430 & 0,414 & 0,400 & $\mathrm{~F}=28,397 /$ sig $=0,000$ \\
\hline Papel Gerencial & $-2,313$ & $-0,178$ & $-0,040$ & 0,557 & 0,592 & $\mathrm{~F}=38,608 / \mathrm{sig}=0,000$ \\
\hline Papel Administrativo & $-1,460$ & $-0,123$ & 0,353 & 0,201 & 0,253 & $\mathrm{~F}=7,531 / \mathrm{sig}=0,000$ \\
\hline Papel de Reporte & $-1,411$ & $-0,125$ & 0,107 & 0,252 & 0,369 & $\mathrm{~F}=7,148 / \mathrm{sig}=0,000$ \\
\hline & & & & & \\
\hline${\text { Incerteza } \text { Ambiental }^{1}}^{-1,080}$ & $-0,093$ & 0,083 & 0,055 & 0,404 & $\mathrm{~F}=4,177 /$ sig $=0,004$ \\
\hline
\end{tabular}

\begin{tabular}{lrrrrrrr}
\hline Setor2 & & & & & & \\
\hline Comércio & 1 & 2 & 0 & 3 & 1 & 7 \\
\hline Indústria & 1 & 11 & 8 & 9 & 15 & 44 & \\
\hline Serviço & 5 & 17 & 9 & 9 & 8 & 48 & $\begin{array}{c}\chi^{2}=9,713 \\
\text { sig=0,286 }\end{array}$ \\
\hline Missings & 2 & 4 & 1 & 2 & 1 & 10 & \\
\hline
\end{tabular}

\begin{tabular}{|c|c|c|c|c|c|c|c|}
\hline Porte (número de funcionários)² & & & & & & & \\
\hline Entre 50 e 249 funcionários & 4 & 4 & 2 & 3 & 2 & 15 & \multirow{4}{*}{$\begin{array}{l}\chi^{2}=17,638 \\
\operatorname{sig}=0,127\end{array}$} \\
\hline Entre 250 e 500 funcionários & 1 & 6 & 2 & 7 & 1 & 17 & \\
\hline Entre 501 e 2000 funcionários & 1 & 9 & 8 & 6 & 11 & 35 & \\
\hline Acima de 2000 funcionários & 3 & 15 & 6 & 7 & 11 & 42 & \\
\hline
\end{tabular}

\begin{tabular}{llllllll}
\hline Empresa $^{\text {multinacional }}{ }^{2}$ & & & & \\
\hline Nacional & 7 & 23 & 14 & 19 & 15 & 78 & $\begin{array}{c}\chi^{2}=3,790 \\
\text { p-valor }=0,435\end{array}$ \\
\hline Multinacional & 2 & 11 & 4 & 4 & 10 & 31 &
\end{tabular}

Nota 1. Para as variáveis papéis do orçamento e incerteza ambiental, foi realizada a Análise Fatorial Confirmatória. As variáveis latentes das funções do orçamento apresentaram validade convergente, discriminante e confiabilidade, conforme parâmetros de Hair Jr. et al. (2016). A variável incerteza ambiental apresentou validade convergente,

discriminante e confiabilidade após a exclusão de um dos três itens ("A dificuldade para prever os eventos futuros impede a empresa de elaborar planos de longo prazo").

Nota 2. Foi realizado o teste ANOVA com os escores padronizados das variáveis latentes para identificar diferença nas médias entre os clusters e o teste Qui-quadrado para as variáveis qualitativas, a fim de identificar possíveis associações em relação aos diferentes clusters. 


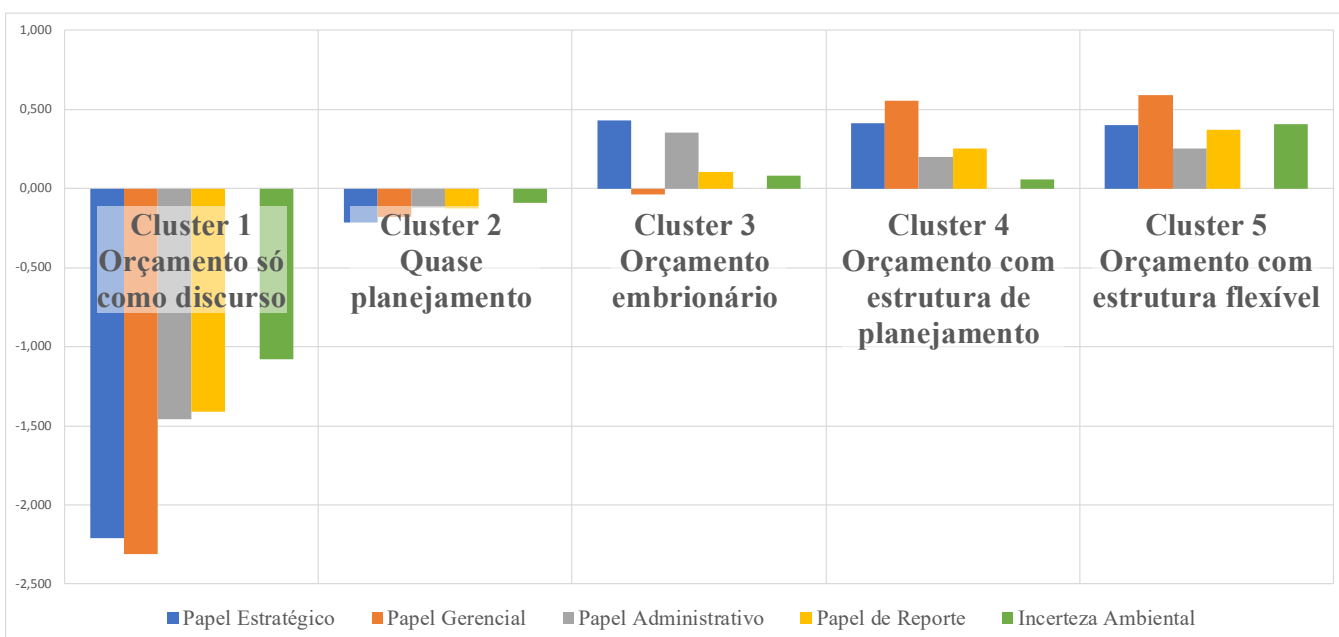

Figura 3. Papéis do orçamento e nível de incerteza nos diferentes clusters.

Nota 1. O eixo vertical consiste na média dos valores dos escores fatoriais padronizados para cada cluster. Essas médias são apresentadas na Tabela 3.

\subsection{Cluster 1: Orçamento só como discurso $(n=9)$}

O Cluster 1 é caracterizado por nível mais baixo de praticamente todas as dimensões do processo orçamentário, com exceção do nível de dificuldade das metas orçamentárias $(0,48)$ e de revisões orçamentárias $(0,55)$.Ao se analisar os papéis do orçamento, percebe-se pouca aderência ao uso do orçamento para desempenhar as funções estratégica, gerencial, administrativa e de reporte. A reflexão que pode emergir é se as empresas desse grupo adotam outras ferramentas para exercer esses papéis. Quanto ao ambiente, identifica-se que as empresas classificadas nesse grupo atuam em contextos com menor nível de incerteza que os demais clusterse não se observou significância estatística pelo teste qui-quadrado para as variáveis porte e atuação multinacional.

Entre as empresas que estão inseridas nesse grupo, os gestores indicam que o orçamento é precário, baseado no feeling e com foco no fluxo de caixa, enquanto o segundo gestor sugere que focam no plano de marketing (projeção de vendas). Destacam-se os seguintes comentários dos gestores:

Nosso orçamento é muito precário, fazemos ele muito baseado no feeling. Não há um processo para isso aqui na empresa. Fazemos um fluxo de caixa nos baseando apenas nos grandes investimentos, nas vendas e nas compras. (respondente de empresa de grande porte do setor comercial atacadista).

O único plano operacional aplicável na empresa é o plano de marketing. Segundo o executivo, "a empresa não tem uma cultura orçamentária forte." (respondente de empresa de médio porte).

A denominação de orçamento só no discurso segue o estudo de Sponem e Lambert (2016) no sentido de que consiste em um instrumento pouco utilizado para acompanhamento, avaliação de desempenho e recompensas, baixa participação e desenvolvimento de planos de ação, mas particularmente envolve um nível alto de dificuldade das metas orçamentárias e um nível superior de revisões orçamentárias em relação aos demais clusters.Percebe-se certo alinhamento desse cluster com o estilo não contábil em que dados contábeis são irrelevantes para avaliação dos centros de custos (Hopwood, 1972) e com o estilo interpessoal que envolve o uso de controles informais para o acompanhamento do desempenho (Merchant, 1981). Por fim, esse perfil está parcialmente alinhado com o Cluster3 proposto por Frezatti et al. (2011), considerando as empresas em que há baixa ênfase no planejamento estratégico e no orçamento. 


\subsection{Cluster 2: Quase Planejamento $(n=34)$}

O processo orçamentário das empresas pertencentes ao Cluster 2 assemelha-se em partes ao Cluster 1 por apresentar um nível baixo em relação à maioria das dimensões analisadas. Nesse sentido, as empresas desse grupo fazem uso de orçamento com maior nível de dificuldade de metas $(0,39)$, de reforescasts $(0,25)$ e de revisões orçamentárias $(0,27)$ e um uso intermediário do orçamento para avaliação de desempenho $(-0,02)$. As empresas classificadas nesse grupo e que reportaram a quantidade de reestimativas realizadas fazem, em média, 3,3 reestimativas das premissas orçamentárias por ano, sendo que duas empresas fazem reestimativas mensais, dezessete empresas fazem reestimativas trimestrais ou quadrimestrais e doze empresas fazem reestimativas semestrais.

Além disso, as empresas desse grupo têm menor nível de participação orçamentária, de proposição de planos de ação de orçamento e uso de recompensas e das características transversais do orçamento (envolvimento de gestores sênior, detalhe e formalização), de forma similar ao Cluster1. As empresas classificadas nesse cluster não percebem com clareza o papel do planejamento em termos estratégico, gerencial, administrativo e de reporte, apresentando nível mais baixo se comparado aos demais clusters, com exceção do Cluster 1. Tendo em vista essas características, esse cluster foi denominado de Quase Planejamento,uma vez que aplicaalgumas das dimensões do orçamento, mas sem demandar algum nível de compromisso em relação ao alcance das metas, assim como as funções do processo orçamentário aparentam ser inócuas nesse grupo.

Em relação ao ambiente, as empresas desse cluster também atuam em um setor com um nível médio de incerteza, o que sugere que o uso de reestimativas pode não ter relação com o ambiente organizacional, mas com o modelo de gestão da organização. Além disso, essas empresas atuamcom maior frequência no setor de serviços e são empresas de grande porte, apesar de essas características não apresentarem significância estatística em relação aos grupos. Esse tipo de processo orçamentário está alinhado com o orçamento indicativo proposto por Sponem e Lambert (2016) ao apresentar um alto nível de dificuldade das metas orçamentárias, mas difere no sentido de que empresas da amostra parecem utilizar ferramentas mais flexíveis como reforecasts e revisões orçamentárias, em um nível superior à média.

\subsection{Cluster 3: Orçamento Embrionário $(n=18)$}

O Cluster 3é caracterizado por um baixo nível de uso do orçamento para avaliação de desempenho $(-0,55)$ e como base para sistema de recompensas $(-1,06)$. Além disso, o Orçamento Embrionário possui um baixo nível de dificuldade nas metas orçamentárias $(0,03)$, bem como de revisões orçamentárias $(-0,06)$. Em relação às outras dimensões, esse grupo apresenta um nível médio em relação às dimensões de participação dos gestores, definição de planos de ação, análise de variação e reforescasts, bem como o envolvimento de executivos, nível de detalhe e de formalização do orçamento.

Quanto às funções, há um nível relativamente alto para as funções estratégica e administrativa alinhada em certa medida com o estilo de orçamento consciente (Hopwood, 1972) e com o controle orçamentário administrativo (Merchant, 1981). Um gestor que atua em uma empresa do setor de serviços sugere o foco do orçamento para previsibilidade e o alinhamento com o longo prazo:

A modelagem que a empresa utiliza contempla uma projeção de 3 a 5 anos. Após essa análise, separamos o primeiro ano que é utilizado de forma mais detalhada para alocar limites de gastos, planos de ações, especificar prioridades etc. (respondente de empresa de grande porte do setor de serviços). 
O gestor de uma empresa industrial de grande porte sugere o uso do orçamento para gestão do fluxo de caixa, que pode abarcar sob certa medida reestimativas (reforescasts) quanto a premissas econômicas:

Acrescento ainda a importância do capital de giro como parte integrante do planejamento financeiro, totalmente integrado a projeção do fluxo de caixa. Determinadas empresas sofrem muito com indicadores econômicos tais como câmbio, preços de commodities, safras de algumas culturas, momento político etc. (respondente de empresa de grande porte do setor industrial).

A denominação de Orçamento Embrionário decorredo foco em metas mais realistas, utilizadas para guiar decisões de gestores, mas não utilizadas formalmente para avaliação de desempenho e recompensas. Cabe destacar que uma das funções mais debatidas na literatura de orçamento é o uso da ferramenta para avaliação de desempenho dos gestores (Hansen \& Van der Stede, 2004). Esse cluster se aproxima do cluster denominado orçamento frouxo no estudo de Sponem e Lambert (2016), mas diferencia-se deste no sentido de que há um acompanhamento de variações e realização de reforescasts, enquanto há um nível mais baixo de revisões orçamentárias. As empresas que compõem esse grupo atuam em um setor com nível mediano de incerteza, se comparada aos outros clusters, e com maior frequência de empresas com atuação no mercado nacional e com mais de 500 funcionários.

\subsection{Cluster 4: Orçamento com estrutura de planejamento estático $(n=23)$}

O Cluster 4 é caracterizado por um nível baixo de adoção de práticas flexíveis de orçamento como reforescasts $(-0,97)$ e revisões orçamentárias $(-0,68)$. As passagens abaixo descrevem um uso mais rígido do orçamento em termos de reestimativas e revisões. Os gestores de empresas do setor industrial, financeiro e agronegócio relatam a importância do orçamento para o processo de planejamento e controle:

A rigidez na elaboração e no cumprimento do orçamento são fatores essenciais para o sucesso do orçamento. (respondente de empresa de grande porte do setor industrial).

Uma vez aprovado em Diretoria e Conselho de Administração, o orçamento não é mais revisado/alterado. (respondente de empresa de grande porte do setor de seguros).

O orçamento original sempre é mantido, pois representa o contrato de metas da gestão. (respondente de empresa de grande porte do setor industrial do agronegócio).

O grupo de orçamento com estrutura de planejamento é caracterizado por um nível alto de envolvimento de executivos seniores $(0,67)$, de detalhe $(0,77)$ e de formalização $(0,67)$, bem como um uso mais forte do orçamento como ferramenta de acompanhamento $(0,51)$, avaliação de desempenho $(0,66)$ e recompensas $(0,88)$. Quanto às funções do orçamento, percebe-se maior grau de aderência aos papéis gerencial e estratégico, corroborando que o orçamento é um mecanismo relevante dentro do processo de controle gerencial. Asseguintes passagens sugerem o uso do orçamento para acompanhamento e avaliação de desempenho:

Na minha empresa o orçamento é base para o planejamento estratégico e operacional da empresa, onde se é comparado o orçado e realizado. E antes do processo de orçamento é realizado um forecast para previsão de fechamento do ano atual e projeção de crescimento do próximo ano. (respondente de empresa de grande porte do setor comercial varejista).

Ele [o orçamento] é um gatilho, ou seja, se não cumprimos o orçamento nãorecebemos bônus. (respondente de empresa de médio porte do setor de serviços de tecnologia da informação). 
As empresas desse cluster atuam em setores que apresentam um nível médio de incerteza, se comparadas aos demais grupos. Esse grupo também apresenta heterogeneidade em relação ao setor e porte das empresas, e uma maior frequência de empresas com atuação nacional.

A denominação de orçamento com estrutura de planejamento estático assemelha-se em partes ao perfil de orçamento coercitivo proposto no estudo de Sponem e Lambert (2016),que é caracterizado por um menor nível de reestimativas e revisões e, em contrapartida, nível médio de acompanhamento de variações e de avaliação de desempenho. O grupo de empresas caracterizadas neste estudo com estrutura de planejamento estático se diferencia do demonstrado por Sponem e Lambert (2016) por possuirum nível superior de recompensas balizadas em metas orçamentárias e um nível relativamente alto de participação dos gestores na proposição de metas. O termo estático está em linha com a teoria da agência no sentido de que o orçamento reflete um compromisso dos gestores com o acionista (buscando estabilizar a questão do valor, objetivos e alinhamento de interesses), enquanto o olhar coercitivo propõe maior ênfase na lógica top down.

Tradicionalmente o orçamento é percebido como um artefato de controle diagnóstico, que envolve a definição de metas, acompanhamento de resultados e avaliação de desempenho. Nesse sentido, encontram-se certas semelhanças entre esse cluster e as seguintes configurações de estudos anteriores: (i) o uso diagnóstico no sentido do acompanhamento dosdesvios do orçamento e do uso do artefato na avaliação de desempenho (Abernethy \& Brownell, 1999); (ii)do uso rígido e coercitivo por apresentar um nível baixo de flexibilidade, expresso em revisões orçamentárias, no alto nível de detalhe e formalização e no alcance estrito das metas orçamentárias (Van der Stede, 2001; Chapman \& Kihn, 2009).

\subsection{Cluster 5: Orçamento com estrutura flexível $(n=25)$}

O Cluster 5 é denominado de orçamento com estrutura flexível e está alinhado com o estudo de Sponem e Lambert (2016) particularmente em relação a um nível alto de participação dos gestores $(0,70)$ e definição de planos de ação no orçamento $(0,62)$, e um nível baixo de dificuldade de alcance das metas orçamentárias $(-0,83)$. Quanto às dimensões de execução e avaliação, esse grupo é caracterizado por um alto nível de acompanhamento de variações orçamentárias $(0,64)$, de reforescasts $(0,77)$ e do uso do orçamento para avaliação de desempenho $(0,43)$ e recompensas $(0,73)$. Em relação às características transversais, há maior envolvimento dos gestores seniores com o orçamento $(0,69)$.

Em relação aos papéis do orçamento, as empresas desse grupo apresentam em média o maior nível para todas as funções sendo a estratégica, gerencial, administrativa e de reporte. Os comentários abaixo reforçam o uso intenso do orçamento pelos executivos:

Hoje, o orçamento na nossa empresa é base para toda a tomada de decisão, o orçamento vem se desenvolvendo cada ano mais(...)(respondente de empresa de grande porte do setor automobilístico).

Na minha empresa o orçamento é a principal ferramenta de definição da estratégia e do acompanhamento da sua execução. (respondente de empresa de grande porte do setor de energia).

Conforme comentado, o grupo de empresas no Cluster 5 faz uso mais intenso de reforescasts, o que reforça um uso intenso e dinâmico do orçamento: "A cada mudança significativa no cenárioeconômico ou da empresa." (respondente de empresa de grande porte do setor de siderurgia). 
Em termos das características organizacionais, as empresas desse grupo são em maior frequência empresas do setor industrial e de grande porte (acima de 500 funcionários) havendo uma participação similar de empresas com atuação nacional e multinacional. Cabe destacar que as empresas desse grupo estão em um ambiente com maior nível de incerteza, e mecanismos como reforecasts e revisões são fundamentais, bem como a intensidade do uso do orçamento em todo o processo de gestão da organização. Além do alinhamento com Sponem e Lambert (2016), esse cluster também possui características semelhantes à tipologia de uso interativo (Abernethy \& Brownell, 1999) e de uso facilitador (Chapman \& Kihn, 2009).

\subsection{Discussão dos clusters}

A partir das configurações de orçamento identificadas, percebem-sequatro grupos de atributos que diferenciam os clusters, os quais estão relacionados às etapas de planejamento, execução e controle, avaliação e as características transversais. O primeiro grupo reflete as características transversais como nível de formalização do processo orçamentário, o nível de detalhamento e o envolvimento dos gestores seniores no processo. As características transversais apresentam-se mais aderentes aos Clusters 3, 4 e 5, as quais são mais fortes no Cluster 4 (Orçamento com estrutura de planejamento). Essas características transversais exibem um nível baixo nos Clusters 1 e 2, o que sugere que, nessas empresas, o processo orçamentário é informal ehá baixo envolvimento dos gestores seniores.

O segundo grupo de características que distinguem os clusters são aquelas relacionadas ao estágio de planejamento. Nesta etapa pode-se perceber que nos Clusters 3,4 e 5 há aderência quanto à participação dos gestores do processo de proposição de metas, bem como na elaboração de planos de ação para o alcance dessas metas, tendo o orçamento uma perspectiva de metas mais realistas (identificado pelo nível de dificuldade das metas), enquanto nos Clusters 1 e 2 o foco é na proposição de metas desafiadoras, em nível superior ao que seria esperado.

O terceiro grupo reflete a etapa de execução e controle do orçamento. Cabe destacar que a análise de variações, comum ao processo de controle, apresenta aderência aos Clusters 3, 4 e 5, demonstrando que nessas empresas há um processo de acompanhamento das variações do resultado realizado em relação ao orçado. Já o reforecast está presente nos Clusters 2, 3 e 5, e especialmente neste último, cujas empresas atuam em um ambiente com maior nível de incerteza $(0,404)$. Quanto às revisões orçamentárias, elas estão presentes particularmente nos Clusters 1 e 2, nos quais o processo orçamentário apresenta-se como mais informal, centralizado, e de certa forma incipiente (devido ao baixo nível das funções desempenhadas pelo orçamento nessas empresas).

O quarto grupo de características relaciona-se com o uso do orçamento para avaliação de desempenho e incentivos. Essas características estão mais presentes nas empresas dos Clusters 4 e 5 em que o orçamento desempenha fortemente a função gerencial eestão pouco presentes nos demais clusters, especialmente o Cluster 3, tendo em vista que nessas empresas o orçamento desempenha as funções estratégica e administrativa. O estudo também demonstra que as configurações do orçamento estão relacionadas a dois aspectos relevantes: as funções que este desempenha nas empresas e o ambiente de incerteza em que a organização atua. De forma geral, percebe-se que a função estratégica está presente nos clusters que possuem aderência às características transversais e de planejamento (participação dos gestores e definição dos planos de ação), sendo eles os Clusters 3, 4 e 5. A função gerencial está presente apenas nos clusters em que há uso do orçamento para avaliação de desempenho e incentivos (Clusters $4 \mathrm{e}$ 5) e a função administrativa aparenta estar relacionada ao acompanhamento do orçamento e à realização de reforescasts. Já a função de reporte apresenta-se mais aderente à configuração em que há estrutura e maior nível de reforescasts (Cluster 5), sendo que essas empresas atuam em ambientes de maior nível de incerteza.Assim, o estudo não traz evidências robustas sobre a relação entre os fatores contingenciais de porte, setor, e mercado de atuação e os perfis de orçamento. 
Por fim, observa-se que, apesar do fato de alguns clusters estarem alinhados aos achados de Sponem e Lambert (2016), o presente estudo avança a literatura prévia ao analisar também o nível de incerteza ambiental e seu reflexo no processo orçamentário. Dessa forma, o contexto de atuação das empresas é tido como relevante na compreensão das características do processo orçamentário, em particular quando se trata de uma economia emergente.

\section{Considerações Finais}

O presente estudo teve como objetivo investigar as diferentes configurações do processo orçamentário utilizado por empresas de médio e grande porte que atuam no Brasil, considerando os estágios de planejamento, de execução, de avaliação e características transversais. Além da proposição dos perfis de desenho do orçamento para o contexto do Brasil, o artigo discute os grupos em relação às funções do orçamento e às características contingenciais (internas e externas), bem como incorpora a percepção dos executivos participantes do estudo. Por meio da abordagem configuracional, oestudo debate sobre os diferentes perfis de desenho do processo orçamentário das empresas, considerando estágios de ausência de orçamento (Só como discurso e Quase planejamento), orçamento embrionário e orçamento com estrutura de planejamento e flexível.

Este trabalho traz evidências adicionais aos achados dos estudos realizados com empresas brasileiras (Frezatti et al., 2011; 2010a), francesas (Sponem \& Lambert, 2016) e americanas e canadenses (Libby \& Lindsay, 2010). Além disso, o presente artigo alinha-se à recomendação de Sponem e Lambert (2016, p. 58) de que a "replicação do estudo em um contexto nacional diferente seria útil para ampliar a generalização dos resultados". Cabe destacar que este estudo difere do de Sponem e Lambert (2016), tendo em vista que os construtos debatidos por esses autores seguem a literatura de uso de orçamento, como,por exemplo,o uso facilitador-coercitivo (Adler \& Borys, 1996) e o uso diagnóstico-interativo (Simons, 1995), enquanto o presente estudo aborda o tópico por meio da discussão de diferentes configuraçõesque refletem os níveis de maturidade do processo nas empresas. Ressalta-se que esta avaliação perpassa também elementos contextuais, como o nível de incerteza ambiental não abarcado por Sponem e Lambert (2016). Deste modo, este estudo dá ênfase à estrutura do processo orçamentário (em termos de múltiplas dimensões), cuja discussão denota diferentes níveis de maturidade,a partirdas funções do orçamento, das características da organização e do contexto em que ela atua. Do ponto de vista prático, este artigotraz insights para o aprimoramento do processo orçamentário das empresas, permitindo uma gestão etomada de decisões mais eficazes, o que por consequência pode ampliar a geração de valor das organizações para os stakeholders.

Os achados do estudo são sujeitos a algumas limitações. Primeiramente, o estudo adota a abordagem descritiva com o objetivo de identificar as características do processo orçamentário que emergem da prática. Além disso, a caracterização está limitada às dimensões e aos instrumentos utilizados no estudo, os quais foram recentemente validados por Sponem e Lambert (2016). As denominações de cada cluster decorrem das características mais evidentes e distintivas dentro de cada grupo, as quais foram debatidas pelos autores de acordo com as evidências empíricas de estudos anteriores. O nível de análise deste estudo é organizacional, no entanto as análises não consideram diferentes percepções sobre o processo orçamentário que pode haver entre sujeitos e/ou áreas dentro de uma organização (Kihn, 2011; Mucci et al., 2016).

O presente trabalho tem implicações para futuros estudos ao abordar de forma ampla os tipos de orçamento que as empresas que atuam no Brasil praticam. A abordagem configuracional permite que pesquisadores e profissionais compreendam as dimensões da prática orçamentária para que possam refletir sobre os dilemas que envolvem o processo e o uso de novas ferramentas para ampliar o papel do orçamento nas organizações. Particularmente, este artigo propõe insights para discussão sobre o nível de maturidade de orçamento implementado porempresas de médio e grande porte, suscitando reflexões a respeito da melhoria do processo orçamentário (dimensões) e ampliação ou delimitação dos papéis que o orçamento desempenha nas empresas. 


\section{Referências}

Abernethy, M. A., \& Brownell, P. (1999). The role of budgets in organizations facing strategic change: an exploratory study. Accounting, Organizations and Society, 24(3), pp. 189-204. Doi: https://doi. org/10.1016/S0361-3682(98)00059-2.

Adler, P. S., \& Borys, B. (1996). Two types of bureaucracy: enabling and coercive. Administrative Science Quarterly, 41(1), pp. 61. Doi: https://doi.org/10.2307/2393986.

Aguiar, A. B. D., Teixeira, A. J., Nossa, V., \& Gonzaga, R. P. (2012). Associação entre sistema de incentivos gerenciais e práticas de contabilidade gerencial. Revista de Administração de Empresas, 52(1), pp. 40-54.Doi: http://dx.doi.org/10.1590/S0034-75902012000100004.

Arnold, M., \& Artz, M. (2019). The use of a single budget or separate budgets for planning and performance evaluation. Accounting, Organizations and Society, 73, pp. 50-67. Doi: https://doi.org/10.1016/j. aos.2018.06.001.

Bedford, D. S., \& Malmi, T. (2015). Configurations of control: an exploratory analysis. Management Accounting Research, 27, pp. 2-26.Doi: https://doi.org/10.1016/j.mar.2015.04.002.

Brownell, P., \& Dunk, A. S. (1991). Task uncertainty and its interaction with budgetary participation and budget emphasis: some methodological issues and empirical investigation. Accounting, Organizations and Society, 16(8), pp. 693-703.Doi: https://doi.org/10.1016/0361-3682(91)90020-f.

Chapman, C. S., \& Kihn, L.-A. (2009). Information system integration, enabling control and performance. Accounting, Organizations and Society, 34(2), pp. 151-169.Doi: https://doi.org/10.1016/j.aos.2008.07.003.

Chenhall, R. H. (2003). Management control systems design within its organizational context: findings from contingency-based research and directions for the future. Accounting, Organizations and Society, 28(2-3), pp. 127-168. Doi: https://doi.org/10.1016/S0361-3682(01)00027-7.

Codesso, M. M., \& Lunkes, R. J. (2016). Disclosure of budgeting planning, execution and control practices: a survey on Brazilian public ports. BASE - Revista de Administração e Contabilidade da UNISINOS, 13(1), pp. 65-78. Doi: https://doi.org/10.4013/base.2016.131.05.

Covaleski, M. A., Evans III, J. H., Luft, J. L., \& Shields, M. D. (2003). Budgeting research: three theoretical perspectives and criteria for selective integration. Journal of Management Accounting Research, 15(1), pp. 3-49.Doi: https://doi.org/10.2308/jmar.2003.15.1.3.

Dal Magro, C. B., \& Lavarda, C. E. F. (2015). Evidências sobre a caracterização e utilidade do orçamento empresarial nas indústrias de Santa Catarina. Advances in Scientific and Applied Accounting, 8(1), pp. 39-062. Doi: https://doi.org/10.14392/ASAA.2015080103.

Dani, A. C., Zonatto, V. C. S., \& Diehl, C. A. (2017). Participação orçamentária e desempenho gerencial: uma meta-análise das relações encontradas em pesquisas desenvolvidas na área comportamental da contabilidade. Advances in Scientific and Applied Accounting, 10(1), 54-72. Doi: https://doi. org/10.14392/ASAA.2017100104.

Dekker, J. C., Lybaert, N., Steijvers, T., Depaire, B., \& Mercken, R. (2013). Family firm types based on the professionalization construct: exploratory research. Family Business Review, 26(1), pp. 81-99.Doi: https://doi.org/10.1177/0894486512445614.

Dess, G. G., Newport, S., \& Rasheed, A. M. (1993). Configuration research in strategic management: key issues and suggestions. Journal of Management, 19(4), pp. 775-795.Doi: https://doi. org/10.1016/0149-2063(93)90027-K. 
Doty, D. H.,\& Glick, W. H. (1994). Typologies as a unique form of theory building: toward improved understanding and modeling. Academy of Management Review, 19(2), pp. 230-251.Doi: https:// doi.org/10.5465/amr.1994.9410210748.

European Commission. (2003). Commission Recommendation of 6 May 2003 concerning the definition of micro, small and medium-sized enterprises. Recuperado em março, 2020 de https://ec.europa.eu/ eurostat/web/structural-business-statistics/structural-business-statistics/sme.

Frezatti, F. (2009). Orçamento empresarial: planejamento e controle gerencial. (6aed.) São Paulo: GEN/Atlas.

Frezatti, F., Aguiar, A. B., Guerreiro, R., \& Gouvea, M. A. (2011). Does management accounting play role in planning process? Journal of Business Research, 64(3), pp. 242-249. Doi: https://doi.org/10.1016/j. jbusres.2009.11.008.

Frezatti, F., Relvas, T. R. S., Nascimento, A. R. do, Junqueira, E. R., \& Bido, D. S. de(2010a). Perfil de planejamento e ciclo de vida organizacional nas empresas brasileiras. Revista de Administração, 45(4), pp. 383-399.Doi: https://doi.org/10.1016/S0080-2107(16)30469-1.

Frezatti, F., Relvas, T. R. S., Junqueira, E., Nascimento, A. R. D., \& Oyadomari, J. C. (2010b). Críticas ao orçamento: problemas com o artefato ou a não utilização de uma abordagem abrangente de análise? ASAA-Advances in Scientific and Applied Accounting, 3(2), pp. 190-216.

Hair Jr., J. F., Black, W. C., Babin, B. J., Anderson, R. E., \& Tatham, R. L. (2009). Análise multivariada de dados. (6a ed.). São Paulo: Bookman.

Hair Jr., J. F., Hult, T. M., Ringle, C. M., \& Sarstedt, M. (2016). A primer on Partial Least Squares Structural Equation Modeling (PLS-SEM). (2nd ed.). Thousand Oaks:Sage.

Hansen, S. C., \& Van der Stede, W. A. (2004). Multiple facets of budgeting: an exploratory analysis. Management Accounting Research, 15(4), pp. 415-439.Doi: https://doi.org/10.1016/j.mar.2004.08.001.

Hartmann, F. G. (2000). The appropriateness of RAPM: toward the further development of theory. Accounting, Organizations and Society, 25(4-5), pp. 451-482.Doi: https://doi.org/10.1016/S0361-3682(98)00036-1.

Hillen, C., \&Lavarda, C. E. F. (2020). Orçamento e ciclo de vida em empresas familiares em processo de sucessão. Revista Contabilidade \& Finanças, 31(83), pp. 212-227. Doi: https://doi.org/10.1590/1808-057x201909600.

Hopwood, A. G. (1972). An empirical study of the role of accounting data in performance evaluation. Journal of Accounting Research, 10, pp. 156-182. Doi: https://doi.org/10.2307/2489870.

Junqueira, E., Caliman, D. R., Frezatti, F., \& Gonzaga, R. P. (2018). Fatores inibidores da institucionalização do processo orçamentário em uma instituição federal de ensino superior. BASE - Revista de Administração e Contabilidade da UNISINOS, 15(3), pp. 178-192.Doi: https://doi.org/10.4013/base.2018.153.02.

Kihn, L. (2011). How do controllers and managers interpret budget targets? Journal of Accounting \& Organizational Change, 7(3), pp. 212-236. Doi: https://doi.org/10.1108/18325911111164187.

Kruis, A. M., Speklé, R. F., \& Widener, S. K. (2016). The levers of control framework: an exploratory analysis of balance. Management Accounting Research, 32, pp. 27-44.Doi: https://doi.org/10.1016/j.mar.2015.12.002.

Libby, T., \& Lindsay, R. M. (2010). Beyond budgeting or budgeting reconsidered? A survey of NorthAmerican budgeting practice. Management Accounting Research, 21(1), pp. 56-75.Doi: https://doi. org/10.1016/j.mar.2009.10.003.

Malmi, T., \& Brown, D. A. (2008). Management control systems as a package. Opportunities, challenges and research directions. Management Accounting Research, 19(4), pp. 287-300.Doi: https://doi. org/10.1016/j.mar.2008.09.003.

Merchant, K. A. (1981). The design of the corporate budgeting system: influences on managerial behavior and performance. Accounting Review, 4, pp. 813-829. Retrieved from https://www.jstor.org/stable/247203. 
Merchant, K. A., \& Manzoni, J. F. (1989). The achievability of budget targets in profit centers: a field study. In Readings in Accounting for Management Control (pp. 496-520). Boston, MA:Springer.

Meyer, A. D., Tsui, A. S., \& Hinings, C. R. (1993). Configurational approaches to organizational analysis. Academy of Management Journal, 36(6), pp. 1175-1195.Doi: https://doi.org/10.5465/256809.

Miles, R.E., \&Snow, C.C. (1978). Organizational strategy, structure, and process. New York: McGraw-Hill.

Miller, D. (1996). Configurations revisited. Strategic Management Journal, 17(7), pp. 505-512.Doi: https:// doi.org/10.1002/(sici)1097-0266(199607)17:7<505::aid-smj852>3.0.co;2-i.

Mintzberg, H.T. (1979). The structuring of organizations. Englewood:Prentice-Hall.

Mucci, D. M., Frezatti, F., \&Dieng, M. (2016). As múltiplas funções do orçamento empresarial. RACRevista de Administração Contemporânea, 20(3), pp. 283-304.Doi: https://doi.org/10.1590/19827849rac2016140121.

Neubaum D. O., Kammerlander N., \&Brigham, K. H. (2019). Capturing family firm heterogeneity: how taxonomies and typologies can help the field move forward. Family Business Review,32(2), pp. 106130. Doi:10.1177/0894486519848512.

Otley, D. (2016). The contingency theory of management accounting and control: 1980-2014. Management Accounting Research, 31, pp. 45-62. Doi: https://doi.org/10.1016/j.mar.2016.02.001.

Shields, J. F., \& Shields, M. D. (1998). Antecedents of participative budgeting. Accounting, Organizations and Society, 23(1), pp. 49-76.Doi: https://doi.org/10.1016/S0361-3682(97)00014-7.

Shields, M. D. (2015). Established management accounting knowledge. Journal of Management Accounting Research, 27(1), pp. 123-132.Doi: https://doi.org/10.2308/jmar-51057.

Silva, M. Z., \& Lavarda, C. E. (2014). Orçamento empresarial: estudo comparativo entre publicações nacionais e internacionais. Revista Base (Administração e Contabilidade) da UNISINOS, 11(3), pp. 179-192.Doi: https://doi.org/10.4013/base.2014.113.01.

Simons, R. (1995). Levers of control: how managers use innovative control systems to drive strategic renewal. USA: Harvard Business School Press.

Speklé, R. F., \& Widener, S. K. (2018). Challenging issues in survey research: discussion and suggestions. Journal of Management Accounting Research, 30(2), pp. 3-21.Doi: https://doi.org/10.2308/jmar-51860.

Sponem, S., \& Lambert, C. (2016). Exploring differences in budget characteristics, roles and satisfaction: a configurational approach. Management Accounting Research, 30, pp. 47-61.Doi: https://doi. org/10.1016/j.mar.2015.11.003.

Van der Stede, W. A. (2001). Measuring 'tight budgetary control'. Management Accounting Research, 12(1), pp. 119-137.Doi: https://doi.org/10.1006/mare.2000.0149.

Van der Stede, W. A., Young, S. M., \& Chen, C. X. (2005). Assessing the quality of evidence in empirical management accounting research: the case of survey studies. Accounting, Organizations and Society, 30(7-8), pp. 655-684.Doi: https://doi.org/10.1016/j.aos.2005.01.003.

Xu, D., \& Meyer, K. E. (2013). Linking theory and context: 'Strategy research in emerging economies' after Wright et al. (2005). Journal of Management Studies, 50(7), pp. 1322-1346. Doi: https://doi. $\operatorname{org} / 10.1111 / j .1467-6486.2012 .01051 . x$.

Young, M. N., Tsai, T., Wang, X., Liu, S., \& Ahlstrom, D. (2014). Strategy in emerging economies and the theory of the firm. Asia PacificJournal of Management, 31(2), pp. 331-354.Doi: https://doi. org/10.1007/s10490-014-9373-0.

Zonatto, V. C. D. S., Nascimento, J. C., Lunardi, M. A., \& Degenhart, L. (2020). Efeitos da participação orçamentária em atitudes gerenciais, satisfação e desempenho gerencial. Revista de Administração Contemporânea, 24(6), pp. 532-549. Doi: https://doi.org/10.1590/1982-7849rac2020200047. 
Apêndice 1. Estatística descritiva dos instrumentos da pesquisa

\begin{tabular}{|c|c|c|c|c|c|c|}
\hline ID & Instrumentos & Média & SD & Mediana & Min & $\operatorname{Max}$ \\
\hline \multicolumn{7}{|c|}{ Estágio do plano } \\
\hline \multicolumn{7}{|c|}{ Participação dos gestores } \\
\hline Part1 & $\begin{array}{l}\text { Os gerentes têm influência decisiva sobre suas metas } \\
\text { orçamentárias }\end{array}$ & 3,6 & 1,0 & 4 & 1 & 5 \\
\hline Part2 & $\begin{array}{l}\text { As metas orçamentárias são decididas em uma } \\
\text { abordagem de baixo para cima (bottom-up) }\end{array}$ & 2,7 & 1,1 & 3 & 1 & 5 \\
\hline Part3 & $\begin{array}{l}\text { Os gerentes desempenham um papel significativo na } \\
\text { elaboração de seus orçamentos }\end{array}$ & 3,9 & 1,1 & 4 & 1 & 5 \\
\hline Part4 & $\begin{array}{l}\text { Quão importante é o papel que os gerentes } \\
\text { desempenham na elaboração de suas previsões } \\
\text { orçamentárias? }\end{array}$ & 4,1 & 1,0 & 4 & 1 & 5 \\
\hline \multicolumn{7}{|c|}{ Tipo de Negociação } \\
\hline ActP1 & $\begin{array}{l}\text { A elaboração de planos de ação é uma etapa } \\
\text { importante no processo orçamentário }\end{array}$ & 3,7 & 1,1 & 4 & 1 & 5 \\
\hline ActP2 & Planos de ação são construídos antes dos orçamentos & 2,8 & 1,2 & 3 & 1 & 5 \\
\hline ActP3 & $\begin{array}{l}\text { Durante as negociações, cada modificação significativa } \\
\text { no orçamento leva a uma modificação dos planos de } \\
\text { ação subjacentes }\end{array}$ & 3,2 & 1,2 & 3 & 1 & 5 \\
\hline ActP4 & $\begin{array}{l}\text { Quão importante é a preparação dos planos de ação } \\
\text { relacionados ao orçamento? }\end{array}$ & 3,8 & 1,2 & 4 & 1 & 5 \\
\hline \multicolumn{7}{|c|}{ Dificuldade no alcance de metas orçamentárias } \\
\hline Dific1 & $\begin{array}{l}\text { A probabilidade de um gerente atingir sua meta de } \\
\text { orçamento é baixa }\end{array}$ & 2,0 & 1,0 & 2 & 1 & 5 \\
\hline Dific2 & Metas orçamentárias são geralmente alcançadas* & 3,8 & 0,8 & 4 & 1 & 5 \\
\hline \multicolumn{7}{|c|}{ Estágio da ação } \\
\hline \multicolumn{7}{|c|}{ Análise de variação } \\
\hline Variance1 & $\begin{array}{l}\text { Ações corretivas devem ser propostas pelos gerentes } \\
\text { quando surge uma variação entre o desempenho real e } \\
\text { o orçado ao longo do ano }\end{array}$ & 4,0 & 1,1 & 4 & 1 & 5 \\
\hline Variance2 & $\begin{array}{l}\text { Grande importância é atribuída à análise das variações } \\
\text { orçamentárias }\end{array}$ & 4,1 & 1,0 & 4 & 1 & 5 \\
\hline Variance3 & $\begin{array}{l}\text { As variações orçamentárias geram discussões entre a } \\
\text { alta administração e o gerente em questão }\end{array}$ & 4,2 & 1,1 & 5 & 1 & 5 \\
\hline \multicolumn{7}{|l|}{ Revisões } \\
\hline Revis1 & $\begin{array}{l}\text { As metas orçamentárias não podem ser alteradas ao } \\
\text { longo do ano* }\end{array}$ & 3,1 & 1,6 & 3 & 1 & 5 \\
\hline \multicolumn{7}{|c|}{ Estágio de revisão e avaliação } \\
\hline \multicolumn{7}{|l|}{ Reforecast } \\
\hline Refor1 & $\begin{array}{l}\text { O orçamento está sujeito a revisão regular para levar } \\
\text { em conta mudanças no ambiente }\end{array}$ & 3,4 & 1,3 & 4 & 1 & 5 \\
\hline Refor2 & $\begin{array}{l}\text { Quantas reestimativas existem, a cada ano, para o } \\
\text { orçamento na empresa? }\end{array}$ & 2,8 & 2,8 & 2 & 0 & 12 \\
\hline \multicolumn{7}{|c|}{ Avaliação baseada no orçamento } \\
\hline PerfEv1 & $\begin{array}{l}\text { Não cumprir as metas orçamentárias reflete } \\
\text { negativamente o desempenho }\end{array}$ & 4,1 & 1,1 & 4 & 1 & 5 \\
\hline PerfEv2 & $\begin{array}{l}\text { Não cumprir as metas orçamentárias tem um impacto } \\
\text { significativo nas avaliações de desempenho dos } \\
\text { gerentes operacionais }\end{array}$ & 3,8 & 1,1 & 4 & 1 & 5 \\
\hline PerfEv3 & $\begin{array}{l}\text { O desempenho dos gerentes operacionais é } \\
\text { primariamente julgado por sua capacidade de cumprir } \\
\text { suas metas orçamentárias }\end{array}$ & 3,2 & 1,1 & 3 & 1 & 5 \\
\hline
\end{tabular}




\begin{tabular}{|c|c|c|c|c|c|c|}
\hline ID & Instrumentos & Média & SD & Mediana & Min & Max \\
\hline \multicolumn{7}{|c|}{ Remuneração baseada no orçamento } \\
\hline Reward1 & $\begin{array}{l}\text { As recompensas baseadas no orçamento compõem } \\
\text { uma alta proporção de salário }\end{array}$ & 2,9 & 1,4 & 3 & 1 & 5 \\
\hline Reward2 & $\begin{array}{l}\text { As recompensas para gerentes operacionais dependem } \\
\text { em grande parte de suas metas orçamentárias }\end{array}$ & 3,1 & 1,4 & 3 & 1 & 5 \\
\hline \multicolumn{7}{|c|}{ Características transversais } \\
\hline \multicolumn{7}{|c|}{ Envolvimento dos gestores seniores no processo orçamentário } \\
\hline Involv1 & $\begin{array}{l}\text { O processo orçamentário está sujeito a análises } \\
\text { frequentes por gerentes em todos os níveis }\end{array}$ & 3,7 & 1,2 & 4 & 1 & 5 \\
\hline Involv2 & $\begin{array}{l}\text { O processo orçamentário está sujeito a análises } \\
\text { frequentes e regulares por parte da alta direção }\end{array}$ & 4,4 & 0,9 & 5 & 1 & 5 \\
\hline Involv3 & $\begin{array}{l}\text { Durante a elaboração do orçamento, há um grande } \\
\text { número de discussões entre a gerência sênior e os } \\
\text { gerentes operacionais }\end{array}$ & 4,0 & 1,1 & 4 & 1 & 5 \\
\hline Involv4 & $\begin{array}{l}\text { A gerência sênior utiliza informações orçamentárias } \\
\text { como forma de questionar e debater as decisões e as } \\
\text { ações dos gerentes operacionais }\end{array}$ & 3,9 & 1,1 & 4 & 1 & 5 \\
\hline \multicolumn{7}{|c|}{ Detalhe de informação no orçamento } \\
\hline Detail1 & $\begin{array}{l}\text { A análise de variação orçamentária para cada gerente } \\
\text { operacional é realizada linha a linha }\end{array}$ & 3,8 & 1,2 & 4 & 1 & 5 \\
\hline Detail2 & $\begin{array}{l}\text { Os relatórios de monitoramento do orçamento não são } \\
\text { muito detalhados e contêm apenas dados agregados* }\end{array}$ & 2,4 & 1,3 & 2 & 1 & 5 \\
\hline Detail3 & $\begin{array}{l}\text { As negociações orçamentárias lidam com orçamentos } \\
\text { muito detalhados }\end{array}$ & 3,6 & 1,2 & 4 & 1 & 5 \\
\hline \multicolumn{7}{|c|}{ Nível de formalização do orçamento } \\
\hline Formal1 & $\begin{array}{l}\text { O processo orçamentário é o mesmo para todos os } \\
\text { centros de responsabilidade }\end{array}$ & 3,8 & 1,3 & 4 & 1 & 5 \\
\hline Formal2 & $\begin{array}{l}\text { Padrões detalhados caracterizam a elaboração do } \\
\text { orçamento (o processo orçamentário é altamente } \\
\text { padronizado) }\end{array}$ & 3,9 & 1,1 & 4 & 1 & 5 \\
\hline
\end{tabular}

Nota 1. Os itens Part2, Variance2, Involv2 e Detail2 foram excluídos por não apresentarem validade convergente e validade discriminante, a partir da análise das cargas fatoriais.

Nota 2. Para os construtos Participação dos gestores e Tipo de Negociação foram utilizadas tanto assertivas quanto perguntas, considerando a escala de 5-pontos.

Nota 3. Para o construto Reforecast foi utilizado um item quantitativo que expressa o número de reestimativas no ano. Nota 4. * Refletem itens com escala reversa. 